\title{
Mobile learning in teaching radiology in times of social isolation
}

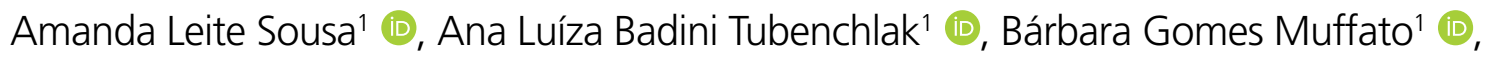

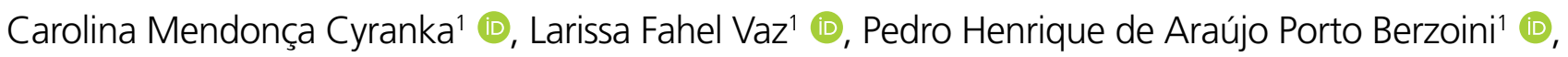 \\ Yves Henrique Faria Dias ${ }^{1} \mathbb{B}$, Gustavo Bittencourt Camilo ${ }^{1 *}$
}

\section{INTRODUCTION}

On March 11, 2020, the World Health Organization declared COVID-19, a highly transmissible disease caused by the severe acute respiratory syndrome coronavirus 2 (SARS-CoV-2) virus, as a pandemic and recommended social isolation as an emergency measure to control the disease. On March 17, 2020, onsite academic activities were suspended indefinitely in the city of Juiz de Fora (MG), Brazil. In view of this, alternative learning strategies were employed in several institutions so that students would not be left unattended.

This present work describes the experience that medical students from a Teaching Institution in Juiz de Fora (MG), members of an Extension Project (EP) in radiology, had with remote teaching - a resource used to keep the project going.

The students expressed their desire to continue with the activities of the EP remotely, but there were some difficulties, such as:

1. Instability of the Internet connection that would not make it possible to attend classes synchronously;

2. Students who had to return to their home cities and did not have adequate equipment to participate in simultaneous classes on educational platforms; and

3. Incompatibility of schedules due to extracurricular tasks.

To remedy these difficulties, it was proposed that the students themselves record content to be watched by their colleagues and by the group advisor according to the availability of each one, asynchronously, with a deadline for the delivery of the responses of the clinical cases presented in the recordings.

The use of technologies as auxiliary tools for education promotes environments of learning opportunities, favors cooperative and collaborative construction through media sharing, and encourages discussions among students1. Over the past decade, there has been a progressive increase in the use of smartphones in different personal and professional contexts, with its use among medical students highly prevalent. These devices can assist in the teaching-learning process, configuring an alternative capable of uniting technology and education: Mobile Learning, M-Learning, or Mobile Learning is an alternative of learning in various contexts, through social interactions, using personal electronic devices2.

Social media is an important tool for collaboration, information, and knowledge sharing between colleagues, as well as between students and facilitators, being useful for improving personal skills and professional communication through continuous posting of photos, videos, audios, and texts. Mobile Learning provides a motivating environment that promotes the development of critical thinking, engagement, motivation, collaboration, and carrying out learning activities through the digital environment2.

The EP students were already included in a group in the WhatsApp ${ }^{\circ}$ application, which did not function as the focus of scientific discussions, since these were held in person every 15 days. During the period of social isolation, the application was chosen by students as a vehicle for discussions and remote learning, considering that it is a free application that allows the transfer of text, images, videos, and audios for groups of people. All of this makes it possible for users to share information in real time in a common interface and with selected members3.

The use of the WhatsApp application in the educational context allows for greater dynamism, ease of interaction, fluency

'Faculdade de Ciências Médicas e da Saúde de Juiz de Fora - Juiz de Fora (MG), Brazil.

Corresponding author: gustavoscamilo@hotmail.com

Conflicts of interest: the authors declare there is no conflicts of interest. Funding: none.

Received on August 29, 2021. Accepted on August 29, 2021. 
in dialogue, and the exchange of information and adherence by students. In addition, it enables an immediate interaction with other platforms to search in real time for articles and evidence that support the discussion and effective learning of students through didactic-pedagogical involvement through a tool used by them routinely 4,5 .

Negative aspects and barriers in the use of social media include:

1. Addiction to social media, which acts as a distractor and distracts students' attention;

2. Cyberbullying;

3. Workload concerns and time constraints;

4. Doubt about the maintenance of privacy and integrity;

5. Lack of interest in feedback from colleagues;

6. Lack of adequate training; and

7. Students who use social media excessively find it difficult to communicate face-to-face 2 . Such effects were minimized due to the emergency and temporary context of the proposed follow-up of the project's activities during the pandemic.

In this way, the Mobile Learning proposal in the context of the pandemic aimed to continue the academic activities in a remote and safe way, guaranteeing the learning of the contents of the radiology discipline through the interaction between students and the teacher responsible for the EP in a group on WhatsApp ${ }^{\oplus}$.

\section{METHODS}

For 4 months, the methodology was applied to a WhatsApp ${ }^{\circ}$ group with 11 members, medical students members of the EP in radiology, and an EP supervising teacher. Initially, it was proposed that each student be responsible every 2 weeks for recording an expository class with topics of relevance in clinical practice combined with image examinations and, at the end of each presentation, clinical cases were exposed so that the other students should solve in a period of up to 1 week.

Synchronous discussions were promoted in the WhatsApp ${ }^{\circ}$ group through radiography and computed tomography examinations, based on real clinical cases, sent by the teacher-advisor in the video format. After sharing the content, the advisor invited the group to discuss the radiological patterns identified and elaborate diagnostic hypotheses, actively participating in the debate as a facilitator and contributing to the quality of the discussion. As they were made live, times were scheduled to be held with as many members as possible.

In addition, the teacher and the students promoted online events in the group, such as congresses, courses, and webinars related to the radiology area, seeking to foster continuous learning through various sources.

\section{RESULTS}

From the students' and supervising professor's point of view, this study gave satisfactory results. For the students, the main positive aspects were the maintenance of the link between the participants of the project, the knowledge acquired in the elaboration and exhibition of the proposed works, as well as the resolution of the questions related to the various themes presented, in addition to stimulating the maintenance of the search for information and knowledge.

Motivational aspects were also mentioned as relevant factors for the continuity of studies and for the search for a more in-depth knowledge on subjects proposed by group participants. In the context of the pandemic, the teaching favored by the new media is innovative, since it changes the conventional learning paradigms, which generally keep teachers and students apart4. In addition, physicians must know how to handle theoretical information from books and scientific articles, as well as to build knowledge in a critical and shared way, using various technologies at their fingertips5.

The use of the WhatsApp group for educational activities, in the context of the EP in radiology, enabled a quick and dynamic dialogue between the members of the group, the sharing of theoretically based information, and the construction of critical and collective knowledge on the part of the group. In addition, the continuity of academic activities, maintained remotely, allowed for the maintenance of the link between students and professor, becoming a stimulus for the search for information.

Another factor of great importance considered by most students was the possibility of using the virtual space to disseminate and stimulate participation in congresses and courses, all carried out online. Some students considered this to be one of the first opportunities for entry and participation in recognized academic means of discussion.

It is important to emphasize that the feasibility of sharing information that could cover different types and levels of difficulty of content in Medicine was also considered a relevant and positive aspect of the project, which were also used by students from different grades (from the third to the eighth grades).

For some group participants, the experience of the EP in radiology exceeded the expectations of the possibilities offered by a usual EP and encouraged the creation of a diary with records of all the activities carried out by the group during the pandemic period (Figure 1A).

The main difficulty presented in relation to the results was the variability of the Internet standard used, which sometimes prevented the questions from being answered immediately when exposed and the insecurity in relation to the possibility of concluding the EP due to the uncertainty of when the return to face-to-face activities would be carried out and how activities carried out during the remote period would be validated. 
(A)

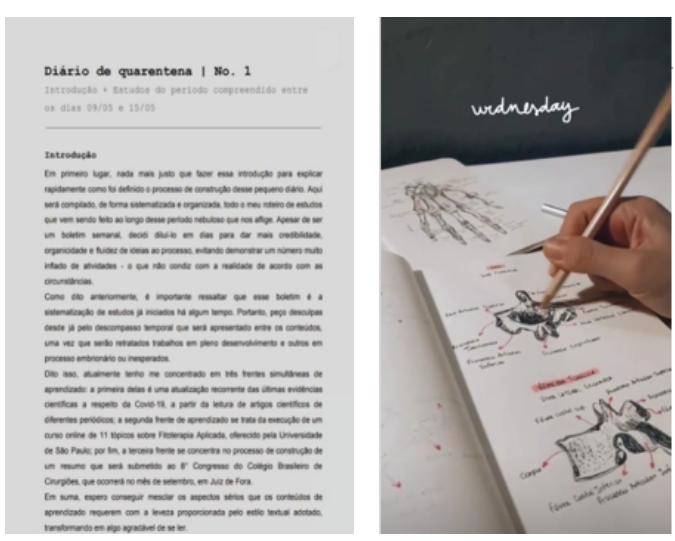

Figure 1. (A) Diary with records of activities carried out by the group during the pandemic period. (B) Drawing of a student from the group who was inspired and motivated to express his study on this form.

For the advisor, the main positive aspect was the confirmation of the students' interest and commitment in the proposed activities. On the other hand, the complicating factor was the impossibility of carrying out the training of students in the practice scenarios. It also highlights the motivational aspect during this tragic period. In a moment of extreme discouragement and uncertainty, the continuity with teaching projects and activities was both a possibility for theoretical and curricular development and a positive psychological stimulus. It is essential to highlight the participation in courses at congresses as well as the possibility for some students to dedicate more time to recreational activities in line with radiology since some even expressed the moment in the form of artistic drawings (Figure 1B).

Since learning is an active process, it is necessary to emphasize that the final result is individual and depends on the interest and commitment of each student.

\section{DISCUSSION}

In the pre-pandemic period, digital learning resources were underemployed in higher education institutions in Brazil, being restricted to only a few sources complementary to the tasks developed in person in the classroom5,6.

With the advent of the public health emergency brought about by the new SARS-CoV-2, the demand for the use of Mobile Learning resources increased due to the social isolation measures required and the closure of teaching and learning institutions followed by the suspension of face-to-face activities.

In this way, teaching platforms such as Microsoft Teams ${ }^{\circ}$, Google Classroom ${ }^{\circ}$, and Zoom ${ }^{\bullet}$ and communication platforms such as Instagram ${ }^{\circ}$ and WhatsApp ${ }^{\circ}$, which previously had other priority purposes, have now been converted into true centers of access and dissemination of knowledge — previously restricted to the physical space of educational institutions.

In this scenario, the platform chosen to continue the EP in radiology, WhatsApp ${ }^{\circ}$, allows the sending of images, videos, voice messages, and other features. This whole framework of applicability helped in the experience and enriched the implemented ones, being essential for learning about radiology. In addition, it is evident that the WhatsApp ${ }^{\oplus}$ communication platform is widely disseminated and used because it allows the creation of groups within the application, making simple and simultaneous contact between EP members at any distance and at any time. In addition, it allows accessibility independent of the mobile device and can be operated on Android ${ }^{\oplus}, \mathrm{iOS}^{\circ}$, or Windows ${ }^{\circ}$.

Nevertheless, WhatsApp ${ }^{\oplus}$ fosters student-student and student-teacher interaction, in addition to providing dynamism to the process, without any additional cost to those involved. This makes it possible to have a questioning reflection on the content and the appearance of doubts — such as which are quickly resolved thanks to the practicality that the application offers.

However, it should be noted that the existence of some obstacles permeates the use of this means of communication in practice. For example, one can mention problems with an Internet connection, the need to have a smartphone, and even the high consumption of cell phone memory by files that need a large storage space can be obstacles to the full enjoyment of the EP.

\section{CONCLUSIONS}

The alternative methodology of Mobile Learning used to continue teaching and extension in the area of radiology remotely by a group of students and teacher in a context of social isolation is easily reproducible and of low cost. In addition, the possibility of using new media and communication vehicles as resources for health education. The activities carried out with the help of the WhatsApp application were useful in learning, sharing ideas, case studies, stimulating learning, and publicizing events. However, it does not replace the knowledge acquired in the student-teacher relationship that occurs in person.

\section{AUTHORS" CONTRIBUTIONS}

ALS: Conceptualization, Writing - original draft. ALBT: Writing - review \& editing. BGM: Writing - original draft, Writing - review \& editing. CMC: Writing - original draft, Writing - review \& editing. LFV: Conceptualization, Writing original draft. PHAPB: Conceptualization, Writing - original draft. YHFD: Conceptualization, Writing - review \& editing. GBC: Conceptualization, Writing - review \& editing. 


\section{REFERENCES}

1. Raiman L, Antbring R, Mahmood A. WhatsApp messenger as a tool to supplement medical education for medical students on clinical attachment. BMC Med Educ. 2017;17(1):7. https:// doi.org/10.1186/s12909-017-0855-x

2. Latif MZ, Hussain I, Saeed R, Qureshi MA, Maqsood $U$. Use of smart phones and social media in medical education: trends, advantages, challenges and barriers. Acta Inform Med. 2019;27(2):133-8. https://doi.org/10.5455/ aim.2019.27.133-138

3. Giansanti D. WhatsApp in mHealth: an overview on the potentialities and the opportunities in medical imaging. Mhealth. 2020;6:19. https://doi.org/10.21037/mhealth.2019.11.01
4. Moran JM. Ensino e aprendizagem inovadores com tecnologias. Informática na Educação: Teoria \& Prática. 2000;3(1):137-44 https://doi.org/10.22456/1982-1654.6474

5. Camilo GB, Junqueira JOG, Teixeira HGC, Resende AB, Oliveira AGF, Mendes PFB, et al. Vascular radiological anatomy and the development of interactive teaching platforms. Sci Med. 2021;31(1):e36944. https://doi.org/10.15448/1980-6108.2021.1.36944

6. Paulino DB, Martins CCA, Raimondi GA, Hattori WT WhatsApp ${ }^{\circledR}$ como recurso para a educação em saúde: contextualizando teoria e prática em um novo cenário de ensino-aprendizagem. Rev Bras Educ Med. 2018;42(1):166-80. https://doi.org/10.1590/1981-52712018v42n1RB20170061 